\title{
Dielectric permittivity of snow measured along the route traversed in the Japanese-Swedish Antarctic Expedition 2007/08
}

\author{
Shin SUGIYAMA, ${ }^{1}$ Hiroyuki ENOMOTO, ${ }^{2}$ Shuji FUJITA, ${ }^{3}$ Kotaro FUKUI, ${ }^{4}$ \\ Fumio NAKAZAWA, ${ }^{3}$ Per HOLMLUND ${ }^{5}$ \\ ${ }^{1}$ Institute of Low Temperature Science, Hokkaido University, Sapporo 060-0819, Japan \\ E-mail: sugishin@lowtem.hokudai.ac.jp \\ ${ }^{2}$ Department of Civil and Environmental Engineering, Kitami Institute of Technology, Koen-cho 165, Kitami 090-8507, Japan \\ ${ }^{3}$ National Institute of Polar Research, 10-3 Midori-cho, Tachikawa, Tokyo 190-8518, Japan \\ ${ }^{4}$ Tateyama Caldera Sabo Museum, 68 Bunazaka, Tateyama-cho, Toyama 930-1405, Japan \\ ${ }^{5}$ Department of Physical Geography and Quaternary Geology, Stockholm University, SE-106 91 Stockholm, Sweden
}

\begin{abstract}
As a joint contribution of Japan and Sweden to the International Polar Year 2007-09, a field expedition between Syowa and Wasa stations in East Antarctica was carried out in the 2007/08 austral summer season. Along the $2800 \mathrm{~km}$ long expedition route, the dielectric permittivity of the upper $1 \mathrm{~m}$ snow layer was measured at intervals of approximately $50 \mathrm{~km}$ using a snow fork, a parallel-wire transmission-line resonator. More than $\mathbf{2 0 0 0}$ measurements were performed under carefully calibrated conditions, mostly in the interior of Antarctica. The permittivity $\varepsilon^{\prime}$ was a function of snow density as in previous studies on dry snow, but the values were significantly smaller than those reported before. In the light of the dielectric mixture theory, the relatively smaller $\varepsilon^{\prime}$ obtained in this study can be attributed to the snow structures characteristic in the studied region. Our data suggest that the permittivity of snow in the Antarctic interior is significantly affected by weak bonding between snow grains, which is due to depth-hoar formation in the extremely low-temperature conditions.
\end{abstract}

\section{INTRODUCTION}

It is essential to determine the dielectric properties of snow to carry out glaciological research in polar regions. The velocity of electromagnetic waves, which must be known for radio-echo soundings in glaciers, ice sheets and snow cover, can be determined from these properties. Satellite remote sensing also requires knowledge of dielectric properties since these control the reflection, scattering, emission and penetration of the waves in a snow layer. Despite its importance, the dielectric nature of snow has not yet been well understood; it is difficult to understand because of the complexity of snow structure and its spatiotemporal variability. For example, in the case of dry snow, the real part of the relative complex permittivity $\varepsilon^{\prime}$ (referred to as the permittivity in this paper) is mostly dependent on the volume fraction of ice and air. However, the influence of snow structure on the permittivity is not clearly understood, although the influence has been predicted in theoretical studies.

The dielectric properties of snow have been measured in the field and laboratories using various instruments. For example, Tiuri and others (1984) used cylindrical cavity resonators to measure the permittivity of snow in Finland. They proposed an empirical relationship between $\varepsilon^{\prime}$ and snow density in microwave frequencies. Similar relationships have been reported in many studies (e.g. Cumming, 1952; Ambach and Denoth, 1980; Hallikainen and others, 1986; Denoth, 1989; Kovacs and others, 1995; Mätzler, 1996). These studies indicate that $\varepsilon^{\prime}$ is mostly controlled by the density, and observed density dependence is consistent with dielectric mixture theory (e.g. Polder and Van Santen, 1946; Taylor, 1965; Tinga and others, 1973). Colbeck (1982) discussed the influence of snow structure on the permittivity using experimental data. This effect is believed to be important for interpreting dielectric properties obtained for different snow conditions. For example, Lytle and Jezek (1994) found that the permittivity of firn from Greenland was dependent on the direction of the electric field. They attributed the observed dielectric anisotropy to the snow grains that were elongated in the vertical direction under the influence of thermal gradient near the surface.

In Antarctica, radio-echo soundings and satellite remote sensing are crucial methods for studying the ice sheet. However, very few ground measurements of dielectric properties have been made, especially for surface snow layers in the interior of the continent. Shiraiwa and others (1996) measured the permittivity and density in the upper $1 \mathrm{~m}$ at six locations between the Mizuho and Dome $\mathrm{F}$ stations in East Antarctica $\left(70.5-74^{\circ} \mathrm{S}, 43-45^{\circ} \mathrm{E} ; 2250\right.$ $3350 \mathrm{~m}$ a.s.I.). The measured $\varepsilon^{\prime}$ was not very well correlated with the snow density. Kärkäs and others (2005) conducted dielectric measurements in 1-2 $\mathrm{m}$ deep snow pits in western Dronning Maud Land $\left(72.5-75^{\circ} \mathrm{S}, 10-16.5^{\circ} \mathrm{W} ; 2250-\right.$ $3350 \mathrm{ma.s.l.}$.). From data obtained using two different instruments, they found relationships between the permittivity and density, but the correlation coefficients were relatively low $(r=0.48$ and 0.59$)$. These studies indicate the complexity of dielectric properties of snow and the difficulties in performing these measurements in the field.

To better understand the physical properties of snow in Antarctica, we carried out $1 \mathrm{~m}$ deep snow-pit measurements during the Japanese-Swedish Antarctic Expedition (JASE) 2007/08. In this paper, we present the results of dielectric measurements conducted in the microwave frequency range. The relationship between the permittivity and snow density was determined using more than 2000 data points collected along the traversed $2800 \mathrm{~km}$ inland route. Our data serve as the basis for snow and ice radar measurements and as a reference for satellite remote sensing in Antarctica. 


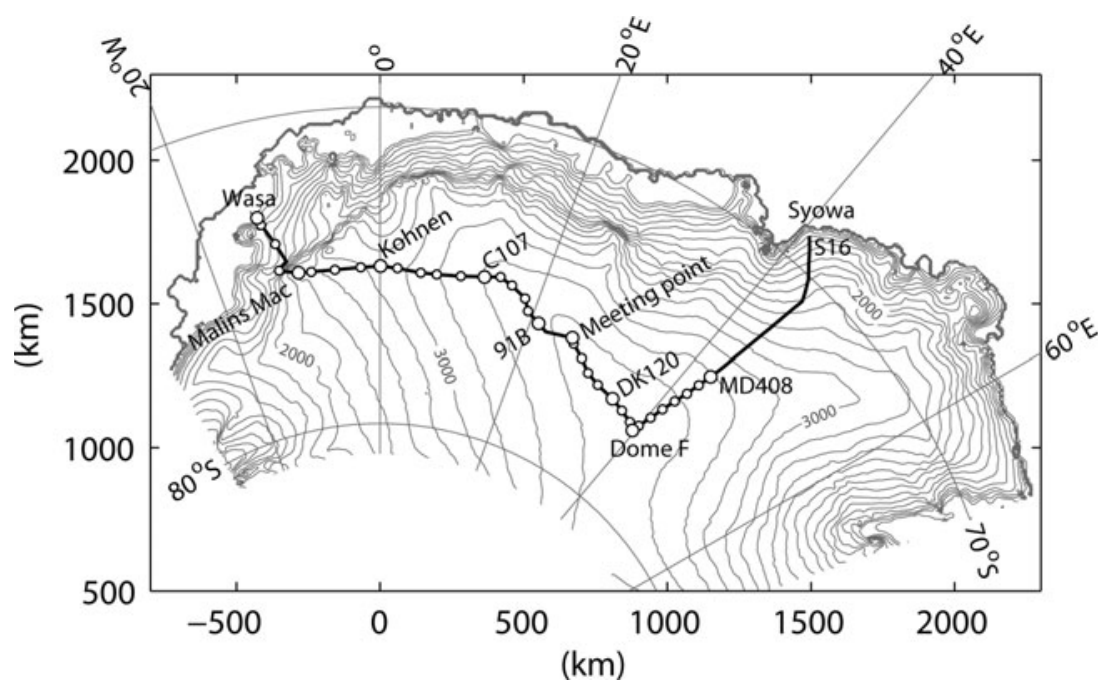

Fig. 1. Map of the studied region of Antarctica along with the route traversed in the JASE 2007/08. Open circles denote the location of the snow-pit measurements. Contour lines represent the surface elevation at intervals of $200 \mathrm{~m}$ based on Bamber and Bindschadler (1997).

\section{METHOD}

\subsection{Study site}

During the 2007/08 austral summer season, a traverse expedition was carried out by Japanese and Swedish teams in East Antarctica between Japanese inland base S16 $(30 \mathrm{~km}$ from Syowa station, $69^{\circ} 03^{\prime} \mathrm{S}, 40^{\circ} 04^{\prime} \mathrm{E}$ ) and Swedish Wasa station $\left(73^{\circ} 04^{\prime} \mathrm{S}, 13^{\circ} 41^{\prime} \mathrm{W}\right.$ ) (Fig. 1; Table 1) (Holmlund and Fujita, 2009). The two teams departed from their home stations in snow vehicles in November 2007 and met at the point $75^{\circ} 89^{\prime} \mathrm{S}, 25^{\circ} 83^{\prime} \mathrm{E}$ on 27 December 2007 . The distance of the meeting point from each of the starting points was approximately $1400 \mathrm{~km}$. The teams exchanged some of the expedition members and scientific instruments before they began their return trips, so that various research activities could be carried out along the entire stretch from S16 to Wasa (approximately $2800 \mathrm{~km}$ ).

The permittivity and density were measured in the upper $1 \mathrm{~m}$ snow layer at 35 locations along the route (Fig. 1; Table 1). The first measurement was made $671 \mathrm{~km}$ inland from S16 (MD408) on 2 December 2007. We repeated the measurements along the rest of the expedition route at intervals of approximately $20-100 \mathrm{~km}$ until the final measurement at Wasa station was completed on 28 January 2008.

Table 1. Sites along the expedition route referred to in the text

\begin{tabular}{|c|c|c|c|c|}
\hline \multirow[t]{2}{*}{ Site } & \multirow[t]{2}{*}{ Long. } & \multirow[t]{2}{*}{ Lat. } & \multirow{2}{*}{$\begin{array}{l}\text { Elevation } \\
\qquad \mathrm{m}\end{array}$} & \multirow{2}{*}{$\begin{array}{c}\text { Distance from } \\
\text { S16 } \\
\text { km }\end{array}$} \\
\hline & & & & \\
\hline S16 & $40^{\circ} 03^{\prime} \mathrm{E}$ & $69^{\circ} 02^{\prime} \mathrm{S}$ & 591 & 0 \\
\hline MD408 & $42^{\circ} 42^{\prime} \mathrm{E}$ & $74^{\circ} 24^{\prime} \mathrm{S}$ & 3485 & 671 \\
\hline Dome F & $39^{\circ} 37^{\prime} \mathrm{E}$ & $77^{\circ} 22^{\prime} \mathrm{S}$ & 3807 & 1005 \\
\hline DK120 & $34^{\circ} 65^{\prime} \mathrm{E}$ & $76^{\circ} 90^{\prime} \mathrm{S}$ & 3757 & 1122 \\
\hline Meeting point & $25^{\circ} 83^{\prime} \mathrm{E}$ & $75^{\circ} 89^{\prime} \mathrm{S}$ & 3661 & 1381 \\
\hline $91 \mathrm{~B}$ & $22^{\circ} 28^{\prime} \mathrm{E}$ & $76^{\circ} 04^{\prime} \mathrm{S}$ & 3566 & 1474 \\
\hline C0107 & $12^{\circ} 53^{\prime} \mathrm{E}$ & $74^{\circ} 58^{\prime} \mathrm{S}$ & 3420 & 1795 \\
\hline Kohnen & $00^{\circ} 04^{\prime} \mathrm{E}$ & $75^{\circ} 00^{\prime} \mathrm{S}$ & 2892 & 2168 \\
\hline Malins Mac & $10^{\circ} 00^{\prime} \mathrm{W}$ & $75^{\circ} 00^{\prime} \mathrm{S}$ & 2532 & 2457 \\
\hline Wasa & $13^{\circ} 41^{\prime} \mathrm{W}$ & $73^{\circ} 04^{\prime} \mathrm{S}$ & 414 & 2764 \\
\hline
\end{tabular}

The elevation of the measurement site increased from $3485 \mathrm{~m}$ (MD408) to $3807 \mathrm{~m}$ (Dome F), and then gradually decreased to $2500 \mathrm{~m}$ at a point $290 \mathrm{~km}$ west of Kohnen station. From this point, the route descended steeply from the high inland plateau to the coastal region. Annual snow layer thicknesses near the surface are $50-200 \mathrm{~mm}$ for the section between MD408 and Dome F (Furukawa and others, 1996), 140-250 $\mathrm{mm}$ in the vicinity of Kohnen (Oerter and others, 1999) and $550 \pm 110 \mathrm{~mm}$ for the coastal region near Wasa (Kärkäs and others, 2005). Thus, the uppermost $1 \mathrm{~m}$ of snow cover consists of several to more than ten annual layers.

\subsection{Permittivity measurements}

The permittivity was measured using Snow Fork model LJ 9902, a microwave resonator probe manufactured by Toikka Engineering Ltd in Finland (Sihvola and Tiuri, 1986). This device measures the resonance spectrum using a parallel-wire transmission-line resonator to determine the complex permittivity in the frequency range $500-900 \mathrm{MHz}$. Its performance was tested and compared with other instruments using Alpine snow (Denoth and others, 1984). The imaginary part of the permittivity can be neglected when the snow is dry, as it is expected to be in the studied region. Thus, we consider only the real part of the permittivity, $\varepsilon^{\prime}$, in this study. The permittivity was calculated from the resonant frequencies measured in air, $f_{\mathrm{a}}$, and snow, $f_{\mathrm{s}}$ :

$$
\varepsilon^{\prime}=\left(\frac{f_{\mathrm{a}}}{f_{\mathrm{s}}}\right)^{2} .
$$

The snow-fork measurement was carried out using a $1 \mathrm{~m}$ deep snow-pit wall (Fig. 2). Parallel wires of the resonator, $60 \mathrm{~mm}$ long and separated by an $18 \mathrm{~mm}$ distance, were pushed into the snow wall at intervals of $30 \mathrm{~mm}$ from the surface to $1 \mathrm{~m}$ depth. We measured the resonant frequency twice at a fixed depth by positioning the parallel wires of the resonator in horizontal and vertical alignment. In these two measurements, the directions of the electric field induced by the resonator are both in the horizontal plane. Reference measurements were made in air before and after a series of the measurements were completed, and the mean value was used for the calculation of $\varepsilon^{\prime}$. The total mean of $f_{\mathrm{a}}$ was 


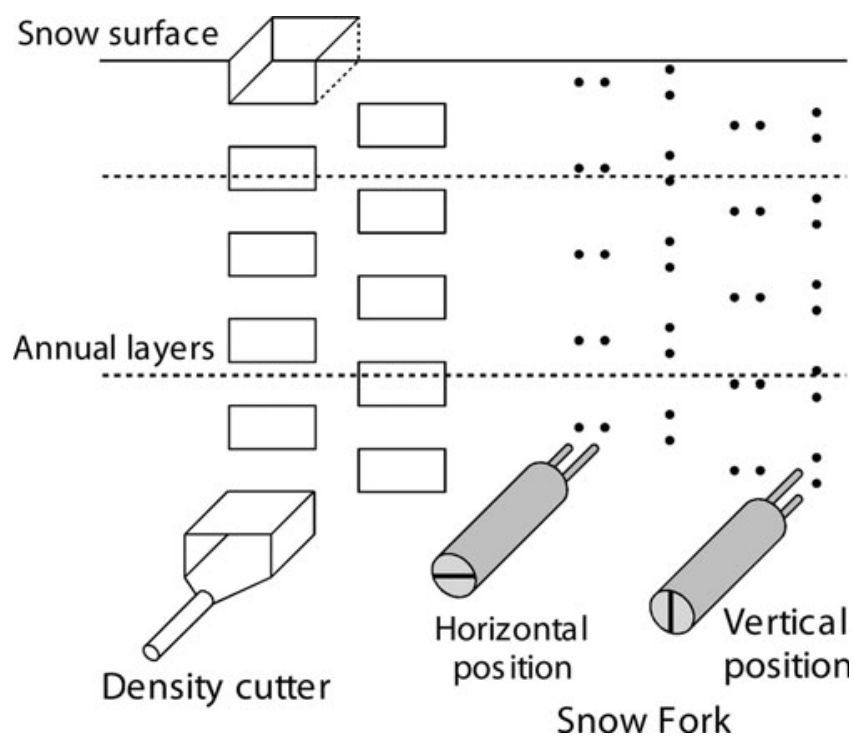

Fig. 2. Schematic diagram showing the permittivity and density measurements. Intervals of the measurements in the vertical direction are $30 \mathrm{~mm}$.

891.7 MHz with a standard deviation of $4.0 \mathrm{MHz}$, which compares with the ideal value of this instrument (887$888 \mathrm{MHz}$ ) within the accuracy of the resonant frequency $( \pm 5 \mathrm{MHz})$. The accuracy of $\varepsilon^{\prime}$ by the snow-fork measurement is reported as $\pm 1.5 \%$, and the possible effect of snow densification due to the insertion of the parallel-wire resonator is +(1.5-3.0)\% (Sihvola and Tiuri, 1986).

\subsection{Density measurements}

The snow density was measured by sampling a $30 \mathrm{~mm}$ thick block using a box-type stainless density cutter $(30 \mathrm{~mm} \times$ $60 \mathrm{~mm} \times 56 \mathrm{~mm}$, Climate Engineering Co.). A digital bench scale (CS200, OHAUS Co.) with a resolution of $\pm 0.1 \mathrm{~g}$ was used for weighing the snow block. The accuracy of the density measured using similar devices is reported as $\pm 4 \%$ (Conger and McClung, 2009). The sampling was performed from the surface to $1 \mathrm{~m}$ depth at intervals of $30 \mathrm{~mm}$ (Fig. 2). The central sampling depth corresponded to the points of the snow-fork measurement, so the density can be compared with the permittivity at the same level. The horizontal distance between the density and snow-fork measurements was within $1 \mathrm{~m}$. Stratigraphical information (snow structure and grain size) was also recorded following the guidelines given by Colbeck and others (1990).

\section{RESULTS}

As typical examples of the measurement data, the vertical profiles of the permittivity and density are shown along with snow stratigraphy (Fig. 3). The structure of the snow in the upper $1 \mathrm{~m}$ snow layer was dominated by faceted crystals (solid-type depth hoar) and depth hoar consisting of medium $(0.5-1.0 \mathrm{~mm})$ to coarse (1.0-2.0) grains (Fig. 4a). For
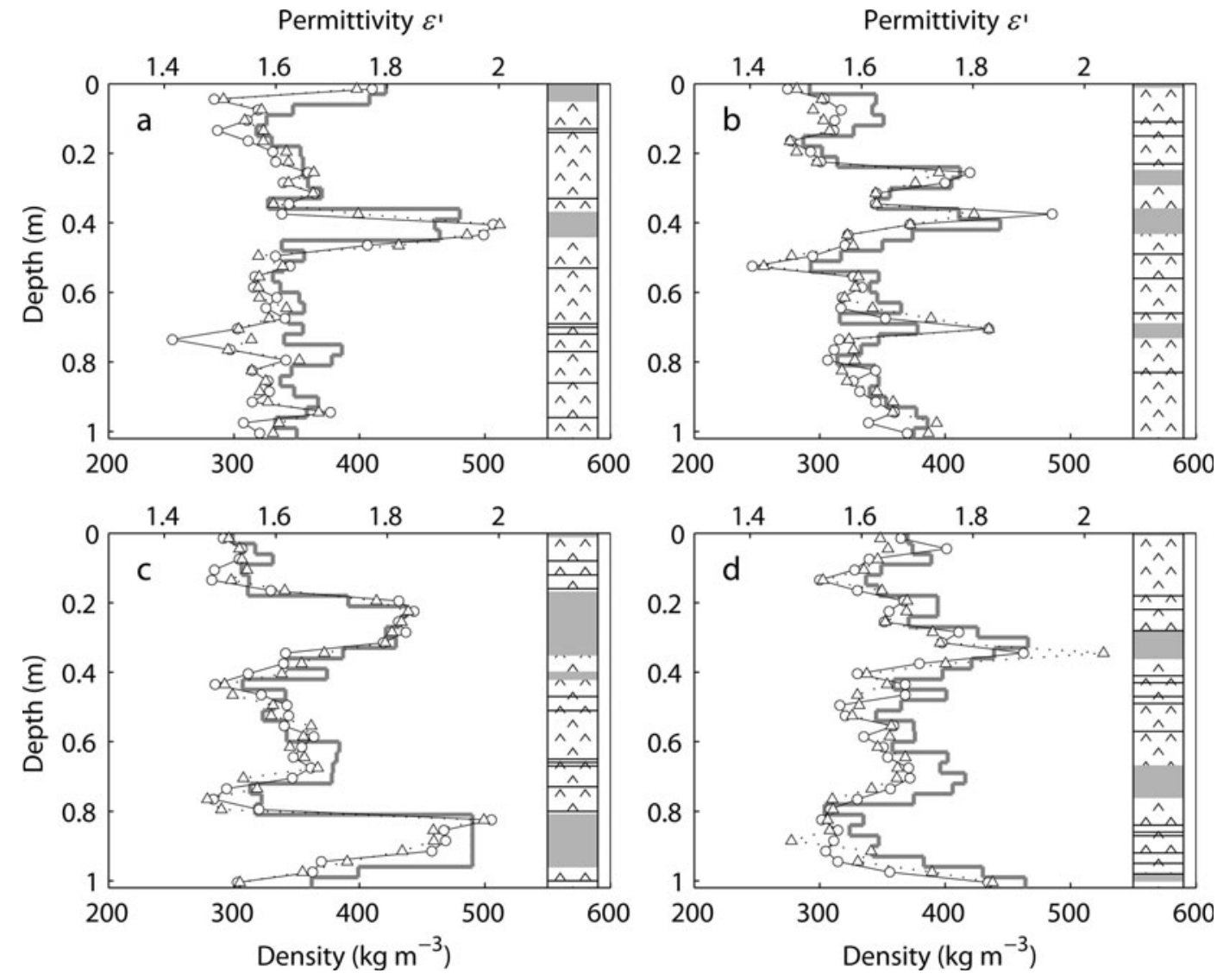

Fig. 3. Permittivity $(\circ, \triangle)$, density (grey line) and stratigraphy measured at (a) DK120 $\left(76^{\circ} 90^{\prime} \mathrm{S}, 34^{\circ} 65^{\prime} \mathrm{E}\right),(\mathrm{b}) 91 \mathrm{~B}\left(76^{\circ} 04^{\prime} \mathrm{S}, 22^{\circ} 28^{\prime} \mathrm{E}\right)$, (c) $\mathrm{C} 0107\left(74^{\circ} 58^{\prime} \mathrm{S}, 12^{\circ} 53^{\prime} \mathrm{E}\right)$ and (d) Malins Mac $\left(75^{\circ} 00^{\prime} \mathrm{S}, 10^{\circ} 00^{\prime} \mathrm{W}\right)$ (Fig. 1; Table 1). The permittivity was measured when the resonator was horizontally $(\circ)$ and vertically $(\triangle)$ positioned. The snow structures are classified as faceted crystals and depth hoar $(\wedge)$, compacted snow (grey) and a crust layer (solid line). 

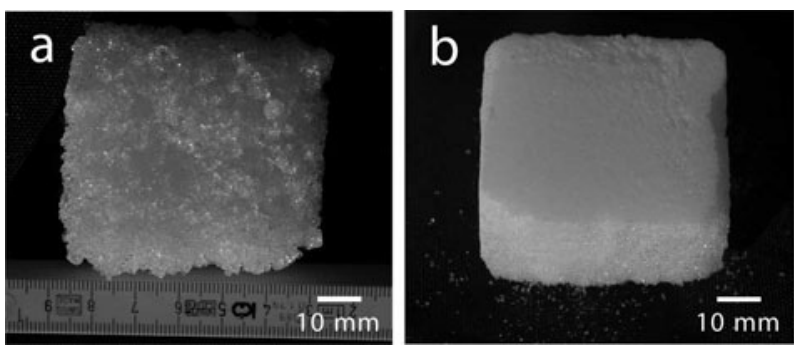

Fig. 4. Photographs of snow samples used for the density measurement: (a) depth hoar and (b) very hard compacted snow.

simplicity, we refer to both these structures as depth hoar in the remainder of this paper. A very hard compacted snow layer with a thickness of $10-100 \mathrm{~mm}$ was also observed. Fine snow grains $(0.2-0.5 \mathrm{~mm})$ were bonded tightly, forming a very hard and relatively dense layer (Fig. 4b). Crust layers with a thickness of several millimeters were also commonly observed.

The vertical profiles show that the permittivity is correlated with the density. The high-density compacted snow layers coincide with the permittivity peaks, as observed for $0.4 \mathrm{~m}$ in Figure 3a. The difference between the measurements obtained when the snow fork is horizontally positioned and those obtained when it is vertically positioned is not clear. Discrepancies between the two methods are observed at the sharp peaks for the high-density layers, but the deviations are not consistent with each other. For example, at $0.4 \mathrm{~m}$ in Figure $3 \mathrm{~b}$ the permittivity is greater when the resonator is horizontally positioned, whereas at $0.35 \mathrm{~m}$ in Figure $3 \mathrm{~d}$ it is greater when the resonator is vertically positioned.

Figure 5 shows the permittivity measurements at the 35 sites; for clarity, only the results from the horizontal positioning of the resonator are shown. The permittivity varies within the range 1.361-2.001, with a total mean of 1.644 and a standard deviation $\sigma=0.102$. The mean value at each sampling site ranges from 1.567 to 1.781 , with $\sigma=0.058$.

The correlation of the permittivity $\varepsilon^{\prime}$ with the density $\rho$ $\left(\mathrm{kg} \mathrm{m}^{-3}\right)$ measured at the same depth was investigated using

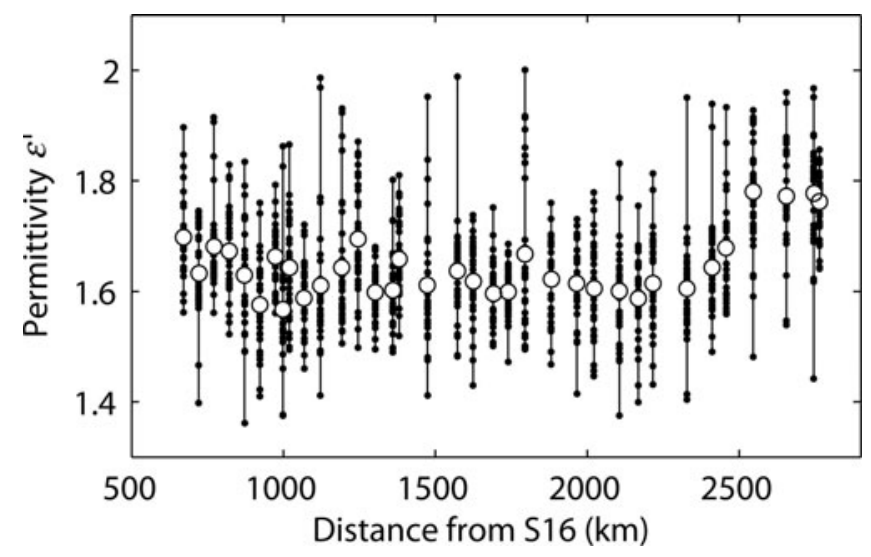

Fig. 5. Permittivity measured along the expedition route. The permittivity was measured with the resonator positioned horizontally. The individual measurements and the mean value for each site are denoted by $(\bullet)$ and (o), respectively.

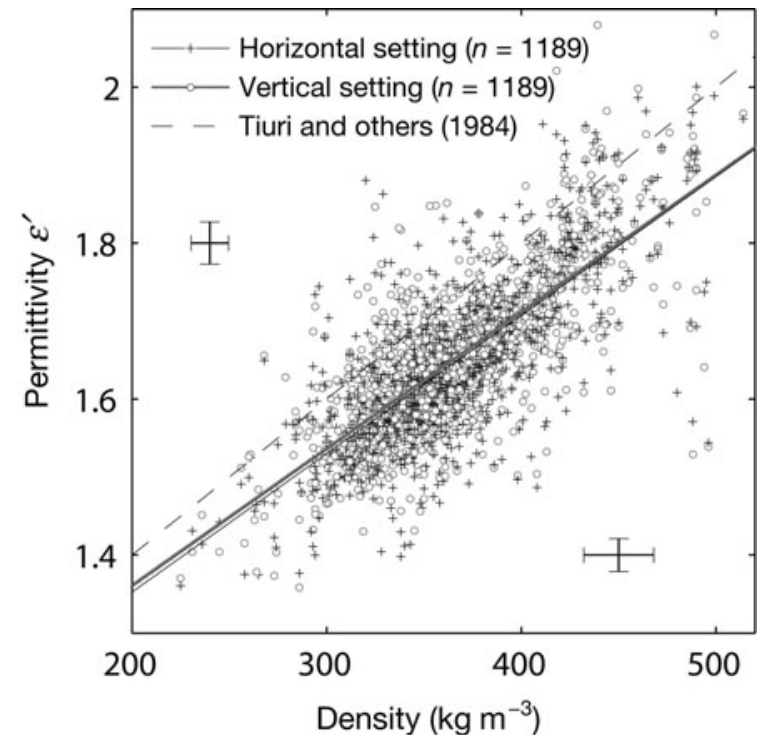

Fig. 6. Plots of all the data on the permittivity vs snow density: the permittivity was measured when the resonator was positioned horizontally (+) and vertically (o). The lines correspond to the linear regression of the two datasets (solid and bold grey lines) and the equation proposed by Tiuri and others (1984) (dashed line). The error bars indicate $\pm 1.5 \%$ and $\pm 4 \%$ errors expected in the permittivity and density measurements, respectively.

all the data obtained in this study (Fig. 6). Least-squares linear regression gives the coefficients of the relationship

$$
\varepsilon^{\prime}=a \rho+b
$$

as $a=0.00178 \mathrm{~kg}^{-1} \mathrm{~m}^{3}$ (95\% confidence interval $(0.00169$, $0.00186))$ and $b=0.997(0.965,1.029)$ with correlation coefficient $r=0.76$ for the horizontal resonator setting, and $a=0.00176(0.00168,0.00184)$ and $b=1.010(0.979$, 1.040) with $r=0.77$ for the vertical setting. Tiuri and others (1984) proposed an empirical relationship with $a=0.002$ and $b=1$. This equation is plotted in Figure 6 for comparison, as it is based on the measurements of various types of snow. Our relationships give a smaller permittivity than Tiuri's equation, and the discrepancy is $0.04-0.1$ (3-5\%) in the density range $200-500 \mathrm{~kg} \mathrm{~m}^{-3}$.

Regression was also performed for non-linear equations used in previous studies (Table 2). Fitting a second-order polynomial to the data (e.g. Denoth, 1989) gives a relationship very similar to the linear regression, and the error increases in the cases of refraction-type (e.g. Kovacs and others, 1995) and Looyenga-type equations (Glen and Paren, 1975).

Table 2. Least-squares regression coefficients and root-mean-square errors (RMSE) determined for the permittivity measured with the resonator positioned horizontally and vertically

\begin{tabular}{lcc}
\hline Equation & Coefficients & RMSE \\
\hline$\varepsilon^{\prime}=a \rho+b$ & $a=0.00177, b=1.003$ & 0.0650 \\
$\varepsilon^{\prime}=a \rho^{2}+b \rho+1$ & $a=8.22 \times 10^{-9}, b=0.00177$ & 0.0650 \\
$\varepsilon^{\prime}=(1+a \rho)^{2}$ & $a=7.75 \times 10^{-4}$ & 0.0657 \\
$\varepsilon^{\prime}=(1+a \rho)^{3}$ & $a=4.94 \times 10^{-4}$ & 0.0664
\end{tabular}


Table 3. Empirical relationships between permittivity $\varepsilon^{\prime}$ and density $\rho\left(\mathrm{kg} \mathrm{m}^{-3}\right)$ proposed for dry snow. The relationship in this study was obtained for the permittivity measured with the resonator positioned horizontally and vertically

\begin{tabular}{|c|c|c|c|c|}
\hline Equation & Snow type & Frequency & $\begin{array}{l}\text { Density } \\
\mathrm{kg} \mathrm{m}^{-3}\end{array}$ & Source \\
\hline$\varepsilon^{\prime}=0.0022 \rho+1$ & Coarse old snow & $\mathrm{MHz}$ range & & Ambach and Denoth (1980) \\
\hline$\varepsilon^{\prime}=0.002 \rho+1$ & Coarse, fine, new, aged and prepared snow & $0.85-12.6 \mathrm{GHz}$ & $100-500$ & Tiuri and others (1984) \\
\hline$\varepsilon^{\prime}=0.00191 \rho+1$ & Natural snow from various depths & $3-37 \mathrm{GHz}$ & $100-450$ & Hallikainen and others (1986) \\
\hline$\varepsilon^{\prime}=4.4 \times 10^{-7} \rho^{2}+0.0019 \rho+1$ & New and old snow, multi-year firn & $10 \mathrm{MHz}$ & $100-650$ & Denoth (1989) \\
\hline$\varepsilon^{\prime}=0.0026 \rho+0.8$ & Greenland firn & $26.5-40 \mathrm{GHz}$ & $350-400$ & Lytle and Jezek (1994) \\
\hline$\varepsilon^{\prime}=\left(8.45 \times 10^{-4} \rho+1\right)^{2}$ & Combination of reported data & $20 \mathrm{MHz}(\mathrm{UHF})$ & $100-900$ & Kovacs and others (1995) \\
\hline$\varepsilon^{\prime}=0.0017 \rho+0.9597$ & Compacted snow & $500-900 \mathrm{MHz}$ & $200-450$ & Shiraiwa and others (1996) \\
\hline$\varepsilon^{\prime}=0.002 \rho+0.9904$ & Antarctic firn & $500-900 \mathrm{MHz}$ & $200-450$ & Kärkäs and others (2005) \\
\hline$\varepsilon^{\prime}=0.00177 \rho+1.003$ & Antarctic firn & $500-900 \mathrm{MHz}$ & $250-500$ & This study \\
\hline
\end{tabular}

\section{DISCUSSION}

The permittivity of snow measured in this study was correlated with the density, and the relationship $\varepsilon^{\prime}(\rho)$ could be approximated by a linear function, as reported in previous studies. The regression lines are essentially identical when the resonator is horizontally and vertically positioned. Thus, we conclude that there is no influence of the measurement method on the relationship between $\varepsilon^{\prime}$ and $\rho$ when the number of measurements is sufficiently large. The measurement was dependent on the resonator position in the vicinity of the high-density layers. This was probably because the permittivity is measured at an exact depth by the horizontally positioned resonator, whereas the mean of an $18 \mathrm{~mm}$ thick layer is measured in the vertical position.

In an interesting observation, the $\varepsilon^{\prime}$ values along the expedition route were smaller than those reported previously for the same density. Previously obtained relationships for dry snow are summarized in Table 3. Except for that obtained by Shiraiwa and others (1996) for dry compacted snow in Japan, the $\varepsilon^{\prime}$ given by these equations is greater than that given by the relationship determined by this study.

The permittivity of dry snow is virtually independent of the microwave frequency in a range that extends up to at least $10 \mathrm{GHz}$ (e.g. Mätzler, 1996). The temperature dependence of $\varepsilon^{\prime}$ for polycrystalline ice is very small $\left(5 \times 10^{-4{ }^{\circ}} \mathrm{C}^{-1}\right.$; e.g. Fujita and others, 1992), and the influence of a quasiliquid layer occurring at the snow particle surface at temperatures above $-10^{\circ} \mathrm{C}$ (Petrenko, 1994) is negligible under the temperature conditions in this study. The effect of dielectric anisotropy of ice crystals (e.g. Matsuoka and others, 1997) under the consideration of dielectric mixture theory (e.g. Polder and Van Santen, 1946) is $<1 \%$. Thus, it is likely that $\varepsilon^{\prime}$ was dependent on the volume fraction of ice and the snow structure. The structural dependence of $\varepsilon^{\prime}$ has been discussed in many studies (e.g. Colbeck, 1982; Denoth, 1982; Sihvola and others, 1985; Kovacs and others, 1995), but little observational evidence has been reported thus far. The structural dependence is hard to prove, as accurate measurements of $\varepsilon^{\prime}$ and $\rho$ in the field are difficult to obtain, and expected difference in $\varepsilon^{\prime}$ is small. Moreover, it is hard to acquire sufficient data for different types of snow structures. By using the large number of data obtained for relatively simple snow structures, we discuss the possible influence of snow structure on the relationship between $\varepsilon^{\prime}$ and $\rho$.
Dry snow can be regarded as a dielectric mixture of ice and air. Applying multiphase dielectric mixture theory, Tinga and others (1973) derived the permittivity of a two-phase mixture with spherical inclusions as follows:

$$
\varepsilon^{\prime}=\frac{3\left(V_{2} / V_{1}\right) \varepsilon_{1}^{\prime}\left(\varepsilon_{2}^{\prime}-\varepsilon_{1}^{\prime}\right)}{\left(2 \varepsilon_{1}^{\prime}+\varepsilon_{2}^{\prime}\right)-\left(V_{2} / V_{1}\right)\left(\varepsilon^{\prime}{ }_{2}-\varepsilon_{1}^{\prime}\right)}+\varepsilon^{\prime}{ }_{1},
$$

where $\varepsilon_{1}$ and $\varepsilon_{2}$ are the permittivity of the host and guest (spherical inclusions) materials, respectively, and $V_{2} / V_{1}$ is the volume fraction of the two materials. By assuming the permittivity of ice to be 3.15 (e.g. Cumming, 1952; Koh, 1992; Fujita and others, 2000), Equation (3) gives the relationships between $\varepsilon^{\prime}$ and $\rho$ for two extreme cases: spherical ice particles surrounded by air and ice containing spherical air bubbles (dashed and solid lines in Fig. 7a). A linear correlation is expected when ice plates are aligned along an electric field (dash-dotted line in Fig. 7a). The bubbly ice has a greater $\varepsilon^{\prime}$ than the spherical ice particles $\left(\Delta \varepsilon^{\prime}=0.136\right.$ at $\left.\rho=400 \mathrm{~kg} \mathrm{~m}^{-3}\right)$, and the majority of our data points lie between the two lines that show these relationships (Fig. 7b). The two structures can be distinguished by the bonding of ice particles. The mixture theory suggests that $\varepsilon^{\prime}$ is larger when the bonding between the snow grains is greater. In our study, the dominant snow structure was the depth hoar, which is characterized by weak bonding of the grains. Therefore, the smaller $\varepsilon^{\prime}$ obtained in our study is possibly due to the snow structure that is characteristic of interior Antarctica. This hypothesis can be understood by considering an analogy with a sintered material. The highly compressed powder has a lower permittivity than the material obtained after a sintering process (Polder and Van Santen, 1946).

Among the data obtained when the resonator was horizontally positioned, those measured in the depth hoar and in the firmly compacted snow are plotted in Figure 8. The linear regression of the two datasets shows that the $\varepsilon^{\prime}(\rho)$ obtained for depth hoar is smaller than that obtained for compacted snow for the same density. The common regression performed for all data (model 1) was compared with the regression performed separately for depth hoar and compacted snow (model 2); the comparison was made by using the $F$ test, a standard statistical method (Weisberg, 1985). $F$ test of model 1 against model 2 gave a significance level much lower than 0.01, which supports the effectiveness of model 2. The compacted snow layer was very hard, indicating that the grains were tightly bonded. Thus, the 

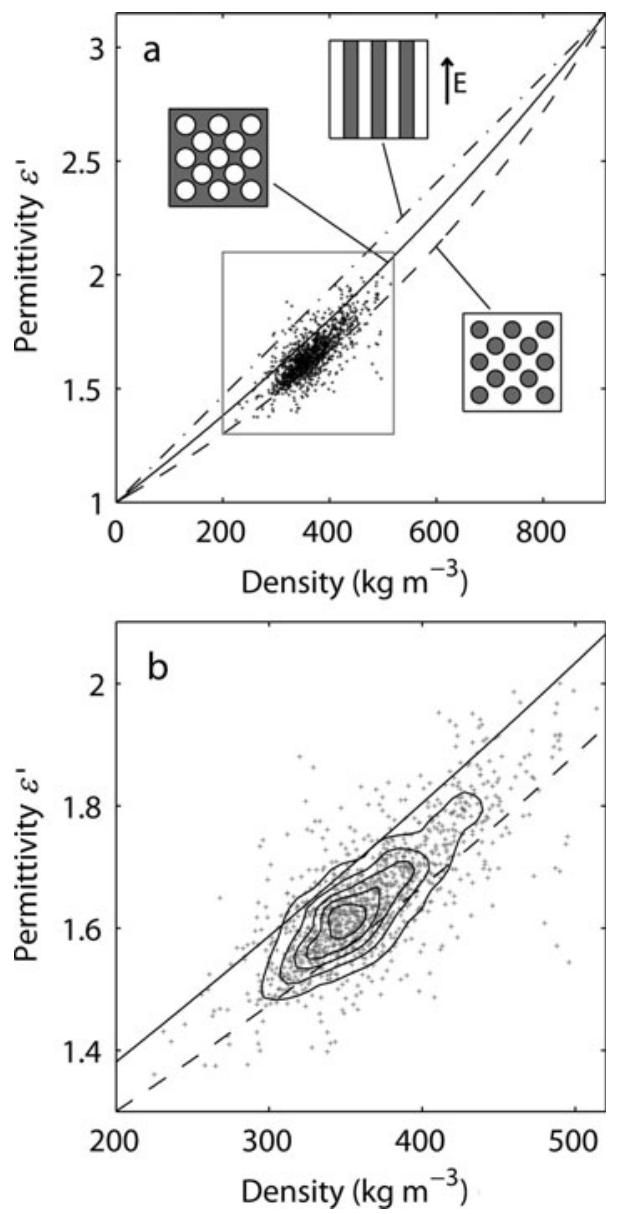

Fig. 7. (a) Plots of the permittivity vs snow density: the dashed, solid and dash-dotted lines represent the relationship given by Equation (3) for the snow structures illustrated by the insets, where ice and air are indicated by grey and white, respectively. The permittivity was measured with the resonator positioned horizontally. (b) Same plot as (a) for the region indicated by the grey box. The contour lines show the data-point density.

regression of the two different snow structures agrees with the hypothesis that the smaller $\varepsilon^{\prime}$ obtained in this study was due to the weak bonding of depth hoar.

Our data also imply structural anisotropy of the snow. Polar firn tends to have weaker grain bonding in the horizontal direction than in the vertical, i.e. the grains are elongated in the vertical direction, as a result of crystal growth in the extremely low-temperature condition. In such structures, the permittivity is expected to be greatest when the electric field is in the vertical direction. Dielectric anisotropy reported for firn in Greenland (Lytle and Jezek, 1994) and in Antarctica (Fujita and others, 2009) is consistent with this assumption. Since the snow-fork measurements in this study used the electric field directed parallel to the horizon, our data imply that the bonding of snow grains in the horizontal direction is very weak in the inland of Antarctica.

\section{CONCLUSION}

The real part of the complex permittivity $\varepsilon^{\prime}$ was measured for the upper $1 \mathrm{~m}$ snow layer along the route traversed in the JASE 2007/08. The result was compared with the snow density $\rho$ to find a relationship between $\varepsilon^{\prime}$ and $\rho$. The

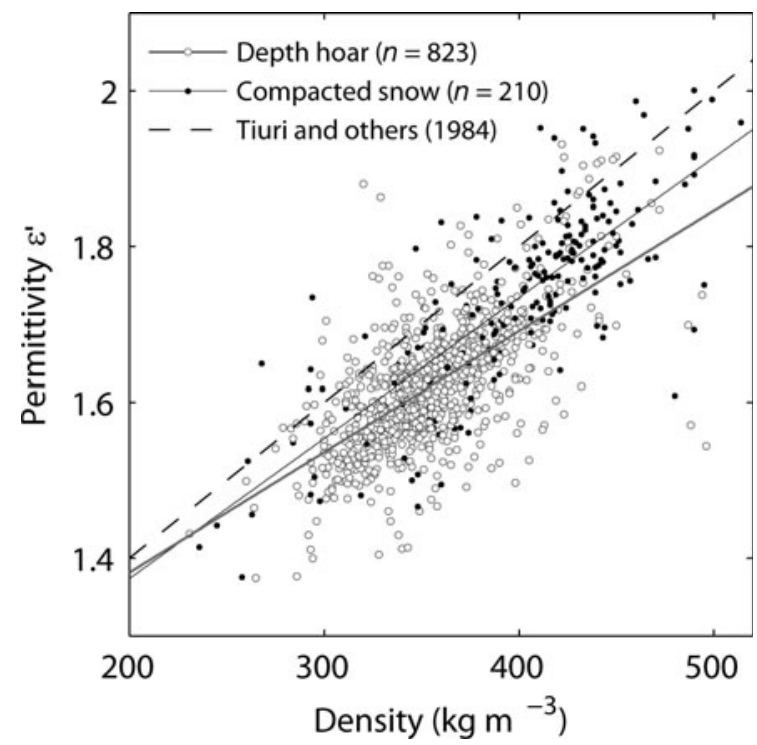

Fig. 8. Plots of the permittivity measured in depth hoar (o) and compacted snow $(\bullet)$ vs snow density. The lines correspond to the linear regression of the two datasets (grey bold and solid lines) and the equation proposed by Tiuri and others (1984) (dash-dotted line). The permittivity was measured with the resonator positioned horizontally.

relationship was determined as $\varepsilon^{\prime}=0.00177 \rho+1.003$ on the basis of more than 2000 data points obtained for 35 locations. This result is independent of the horizontal and vertical positions of a parallel-wire resonator of the measurement device. The values of $\varepsilon^{\prime}$ given by this equation are $3-5 \%$ smaller than those reported previously in the density range $200-500 \mathrm{~kg} \mathrm{~m}^{-3}$. The smaller permittivity suggests the effect of snow structure on the dielectric properties. A majority of the measurements were made in the depth hoar that is characterized by the weak bonding of snow grains. According to the dielectric mixture theory, the permittivity of such structures is smaller than that of snow consisting of tightly bonded grains.

\section{ACKNOWLEDGEMENTS}

We thank the members of the JASE 2007/08 for their help in the field. The field activity was a part of the 48th and 49th Japanese Antarctic Research Expedition and supported by the National Institute of Polar Research, Tokyo, and the Swedish Polar Research Secretariat. The snow fork was kindly loaned by K. Fujita of Nagoya University. The surface elevation data used for the map were provided by the US National Snow and Ice Data Center. We thank two anonymous referees for providing careful reviews, and the scientific editor A.M. Smith for handling the paper. This study was funded by the Japanese Ministry of Education, Science, Sports and Culture, Grant-in-Aid for Scientific Research (A), 20241007, 2008-2010.

\section{REFERENCES}

Ambach, W. and A. Denoth. 1980. The dielectric behaviour of snow: a study versus liquid water content. In Rango, A., ed. Microwave remote sensing of snowpack properties. Washington, DC, National Aeronautics and Space Administration, 69-91. (NASA CP-2153.) 
Bamber, J.L. and R.A. Bindschadler. 1997. An improved elevation dataset for climate and ice-sheet modelling: validation with satellite imagery. Ann. Glaciol., 25, 439-444.

Colbeck, S.C. 1982. The geometry and permittivity of snow at high frequencies. J. Appl. Phys., 53(6), 4495-4500.

Colbeck, S.C. and 7 others. 1990. The international classification for seasonal snow on the ground. Wallingford, Oxon, International Association of Scientific Hydrology. International Commission on Snow and Ice.

Conger, S.M. and D.M. McClung. 2009. Comparison of density cutters for snow profile observations. J. Glaciol., 55(189), 163-169.

Cumming, W.A. 1952. The dielectric properties of ice and snow at 3.2 centimeters. J. Appl. Phys., 23(7), 768-773.

Denoth, A. 1982. Effect of grain geometry on electrical properties of snow at frequency up to $100 \mathrm{MHz}$. J. Appl. Phys., 53(11), 7496-7501.

Denoth, A. 1989. Snow dielectric measurements. Adv. Space Res., 9(1), 233-243.

Denoth, A. and 6 others. 1984. A comparative study of instruments for measuring the liquid water content of snow. J. Appl. Phys., 56(7), 2154-2160.

Fujita, S., M. Shiraishi and S. Mae. 1992. Measurement on the microwave dielectric constant of ice by the standing wave method. In Maeno, N. and T. Hondoh, eds. Proceedings of the International Symposium on the Physics and Chemistry of Ice. Sapporo, Hokkaido University Press, 415-421.

Fujita, S., T. Matsuoka, T. Ishida, K. Matsuoka and S. Mae. 2000. A summary of the complex dielectric permittivity of ice in the megahertz range and its applications for radar sounding of polar ice sheets. In Hondoh, T., ed. Physics of ice core records. Sapporo, Hokkaido University Press, 185-212.

Fujita, S., J. Okuyama, A. Hori and T. Hondoh. 2009. Metamorphism of stratified firn at Dome Fuji, Antarctica: a mechanism for local insolation modulation of gas transport conditions during bubble close off. J. Geophys. Res., 114(F3), F03023. (10.1029/2008JF001143.)

Furukawa, T., K. Kamiyama and H. Maeno. 1996. Snow surface features along the traverse route from the coast to Dome Fuji Station, Queen Maud Land, Antarctica. Proc. NIPR Symp. Polar Meteorol. Glaciol., 10, 13-24.

Glen, J.W. and J.G. Paren. 1975. The electrical properties of snow and ice. J. Glaciol., 15(73), 15-38.

Hallikainen, M.T., F.T. Ulaby and M. Abdelrazik. 1986. Dielectric properties of snow in the 3 to $37 \mathrm{GHz}$ range. IEEE Trans. Antennas Propag., 34(11), 1329-1340.

Holmlund, P. and S. Fujita. 2009. Japanese-Swedish Antarctic Expedition, JASE. In Thorén, A., ed. Swedish Polar Secretariat
Year Book 2008. Stockholm, Swedish Polar Research Secretariat, 18-21.

Kärkäs, E., T. Martma and E. Sonninen. 2005. Physical properties and stratigraphy of surface snow in western Dronning Maud Land, Antarctica. Polar Res., 24(1-2), 55-67.

Koh, G. 1992. Dielectric constant of ice at 26.5-40 GHz. J. Appl. Phys., 71(10), 5119-5122.

Kovacs, A., A.J. Gow and R.M. Morey. 1995. The in-situ dielectric constant of polar firn revisited. Cold Reg. Sci. Technol., 23(3), 245-256.

Lytle, V.I. and K.C. Jezek. 1994. Dielectric permittivity and scattering measurements of Greenland firn at $26.5-40 \mathrm{GHz}$. IEEE Trans. Geosci. Remote Sens., 32(2), 290-295.

Matsuoka, T., S. Fujita, S. Morishima and S. Mae. 1997. Precise measurement of dielectric anisotropy in ice lh at $39 \mathrm{GHz}$. J. Appl. Phys., 81(5), 2344-2348.

Mätzler, C. 1996. Microwave permittivity of dry snow. IEEE Trans. Geosci. Remote Sens., 34(2), 573-581.

Oerter, H., W. Graf, F. Wilhelms, A. Minikin and H. Miller. 1999. Accumulation studies on Amundsenisen, Dronning Maud Land, by means of tritium, dielectric profiling and stable-isotope measurements: first results from the 1995-96 and 1996-97 field seasons. Ann. Glaciol., 29, 1-9.

Petrenko, V.F. 1994. The surface of ice. CRREL Spec. Rep. 94-22.

Polder, D. and J.H. van Santen. 1946. The effective permeability of mixtures of solids. Physica, 12(5), 257-271.

Shiraiwa, T., H. Shoji, T. Saito, K. Yokoyama and O. Watanabe. 1996. Structure and dielectric properties of surface snow along the traverse route from coast to Dome Fuji Station, Queen Maud Land, Antarctica. Proc. NIPR Symp. Polar Meteorol. Glaciol., 10, 1-12.

Sihvola, A. and M. Tiuri. 1986. Snow fork for field determination of the density and wetness profiles of a snow pack. IEEE Trans. Geosci. Remote Sens., 24(5), 717-721.

Sihvola, A., E. Nyfors and M. Tiuri. 1985. Mixing formulae and experimental results for the dielectric constant of snow. J. Glaciol., 31(108), 163-170.

Taylor, L. 1965. Dielectric properties of mixtures. IEEE Trans. Antennas Propag., 13(6), 943-947.

Tinga, W.R., W.A.G. Voss and D.F. Blossey. 1973. Generalized approach to multiphase dielectric mixture theory. J. Appl. Phys., 44(9), 3897-3902.

Tiuri, M.T., A.H. Sihvola, E.G. Nyfors and M.T. Hallikainen. 1984. The complex dielectric constant of snow at microwave frequencies. IEEE J. Ocean. Eng., 9(5), 377-382.

Weisberg, S. 1985. Applied linear regression. Second edition. New York, etc., John Wiley and Sons. 